\title{
Accuracy of Unstimulated Basal Serum Thyroglobulin Levels in Assessing the Completeness of Thyroidectomy
}

\author{
Emin Gurleyik ${ }^{\mathrm{a}, \mathrm{b}}$, Sami Dogan ${ }^{\mathrm{a}}$
}

\begin{abstract}
Background: Complete excision is important for proper surgical treatment of thyroid disorders. Functional thyroid tissue can be identified based on the level of serum thyroglobulin (Tg), which is produced only by the thyroid follicular cells, and nuclear scan.
\end{abstract}

Methods: Serum thyroid stimulating hormone (TSH), free thyroxin (FT4), basal (unstimulated) Tg and anti-Tg antibody (anti-Tg ab) were measured at the sixth postoperative month in 100 patients with benign thyroid disorders treated by total thyroidectomy. Thyroid nuclear scan was obtained to identify functional remnant of the thyroid gland. The sensitivity, specificity, accuracy, positive predictive value (PPV) and negative predictive value (NPV) of the Tg levels in assessing thyroid remnant were calculated.

Results: Positive scan showed thyroid remnant in 23 patients, among whom 16 were $\mathrm{Tg}$ positive (true positive) and seven were $\mathrm{Tg}$ negative $(<0.5 \mathrm{ng} / \mathrm{mL})$ (false negative). In these patients, the nuclear scan revealed pyramidal lobe remnants. In 77 patients with negative scan, the $\mathrm{Tg}$ levels were also negative (true negative), and the PPV, NPV, sensitivity, specificity and accuracy of the Tg levels were $100 \%, 92 \%, 70 \%, 100 \%$ and $93 \%$, respectively.

Conclusions: The positive basal $\mathrm{Tg}(>0.5 \mathrm{ng} / \mathrm{mL})$ level accurately indicated the functional thyroid remnant after total thyroidectomy. The negative $\mathrm{Tg}(<0.5 \mathrm{ng} / \mathrm{mL})$ level supported complete excision of the thyroid gland. The surgical completeness of total thyroidectomy was accurately evaluated based on the serum Tg levels. Therefore, serum Tg levels should be measured in postoperative follow-up to determine the completeness of total thyroidectomy.

Keywords: Thyroid; Benign disorders; Surgery; Thyroglobulin; Nuclear scan

\footnotetext{
Manuscript accepted for publication May 26, 2014

${ }^{a}$ Department of Surgery, Faculty of Medicine, Duzce University, Duzce, Turkey

${ }^{\mathrm{b}}$ Corresponding Author: Emin Gurleyik, Universite Hastanesi, Konuralp, Duzce 81650 Turkey. Email: egurleyik@yahoo.com
}

doi: http://dx.doi.org/10.14740/jocmr1873w

\section{Introduction}

Total thyroidectomy is the surgical procedure of choice for majority of patients with thyroid gland disorders. The total removal of the gland requires complete excision of all the thyroidal tissue. The completeness of thyroidectomy has great surgical importance, mainly owing to the necessity for providing definitive treatment of both benign and malignant diseases, as well as preventing recurrence and secondary surgery. In addition, the completeness of thyroidectomy is important for sensitive and appropriate follow-up of malignant cases with biochemical analyses, nuclear medicine studies, etc. Completeness of thyroidectomy is generally assessed by examination of the presence of functional thyroidal tissue in the neck by nuclear medicine procedures. In several cases, screening with some nucleotides may not establish the presence of functional thyroidal tissue. Moreover, some focal uptakes of nucleotides in the neck do not always accurately evaluate the functional capacity and prognostic importance of the remaining tissue.

Thyroglobulin ( $\mathrm{Tg}$ ) is a large glycoprotein (MW: $660,000)$ stored in the thyroid follicles and produced only by the thyroid follicular cells in benign condition [1]. However, it is also produced by well-differentiated cancer cells in malignant conditions. The presence of significant amount of $\mathrm{Tg}$ in the serum sensitively shows the presence of functional thyroidal tissue in the body. We hypothesize that the completeness of thyroidectomy can be assessed by serum $\mathrm{Tg}$ levels. Hence in the present study, we aimed to determine the accuracy of serum Tg levels in assessing the completeness of thyroidectomy after surgical treatment of benign thyroid disorders.

\section{Patients and Methods}

Between January 2010 and July 2013, a prospective study was conducted on patients with surgical thyroid diseases. Based on the following criteria, a total of 100 patients with total thyroidectomy for benign disorders were included this study: 1) The patients should have undergone total thyroid- 
Table 1. Results of Serum Thyroglobulin (Tg) Levels and Nuclear Scan of the Thyroid Gland

\begin{tabular}{llll}
\hline & Scan negative $(\mathbf{n}=\mathbf{7 7})$ & Scan positive $(\mathbf{n}=\mathbf{2 3})$ & Total \\
\hline Tg negative $(<0.5 \mathrm{ng} / \mathrm{mL})$ & True negative $77(100)^{*}$ & False negative $7(30)$ & 84 \\
Tg positive $(>0.5 \mathrm{ng} / \mathrm{mL})$ & False positive 0 & True positive $16(70)$ & 16 \\
Total & 77 & 23 & 100 \\
\hline
\end{tabular}

*Numbers in parentheses are percentages.

ectomy. 2) Presence of benign disorders of the thyroid gland. 3) Patients with reoperative surgery were not included. 4) Total thyroidectomy should have been performed by the same surgeon to provide standard surgical technique. 5) Prescription of thyroid hormone (thyroxin; LT4) replacement postoperatively to maintain normal serum thyroid stimulating hormone (TSH) levels. 6) At the end of the sixth postoperative month, the serum TSH, free thyroxin (FT4), Tg and anti-Tg antibody (anti-Tg ab) levels were determined by biochemical analyses. 7) Total thyroidectomy cases with negative $(<2.2 \mathrm{IU} / \mathrm{mL})$ anti-Tg ab levels were included. 8) Thyroid nuclear scan (with technetium $99 \mathrm{~m}$ pertechnetate) was obtained to identify the presence of functional remnant tissue of the thyroid gland.

The term "nuclear scan positive" indicated thyroid scintigraphy showing thyroid remnant in the neck. "Serum Tg negative" denoted basal (unstimulated) Tg levels $<0.5 \mathrm{ng} /$ $\mathrm{mL}$. "True negative" indicated Tg levels $<0.5 \mathrm{ng} / \mathrm{mL}$ in patients with negative nuclear scan image. "True positive" denoted Tg levels $>0.5 \mathrm{ng} / \mathrm{mL}$ in patients with positive nuclear scan image (Table 1). The sensitivity, specificity, accuracy, positive predictive values (PPV) and negative predictive values (NPV) of the serum Tg levels in assessing the completeness of thyroidectomy were calculated.

\section{Results}

A total of 73 patients were women with a mean age of 54 years (range, 33 - 71 years). The serum Tg levels were negative $(<0.5 \mathrm{ng} / \mathrm{mL})$ in all the 77 patients who had no functional remnant of the thyroid gland (negative nuclear scan; true negative). Postoperative nuclear scan of the gland showed small thyroid remnants in 23 patients. The thyroid remnant was present (positive nuclear scan) in all 16 patients with positive Tg levels (true positive). However, the serum $\mathrm{Tg}$ levels were also negative in seven (of 23) patients with positive nuclear scan (false negative in $7 \%$ of the patients) (Table 1). In the positive nuclear scan cases, the focal uptake of the radionuclide was determined in the midline, which indicated pyramidal lobe (PL) remnant (Fig. 1-3).
The sensitivity of the serum Tg levels in assessing the completeness of thyroidectomy was $70 \%$. Furthermore, the specificity, accuracy, PPV and NPV of the serum Tg levels were $100 \%, 93 \%, 100 \%$ and $92 \%$, respectively.

\section{Discussion}

Total thyroidectomy is the current surgical procedure of choice for patients with thyroid gland disorders. Complete excision of the thyroid tissue is important for definitive treatment of the disease, prevention of recurrence and secondary surgery, and sensitive follow-up of malignant cases with $\mathrm{Tg}$ measurement. Tg is known to be a sensitive marker of functional benign or malignant foci of the thyroid tissue. Recent studies have reported that sequential measurement of the basal serum Tg level is more effective in detecting the functional remnant of the thyroid gland after total excision $[1,2]$. The $99 \mathrm{~m}$ Tc pertechnetate scintigraphy is a simple and feasible tool to evaluate the thyroid remnants after thyroidectomy [3]. The unstimulated baseline Tg values during TSH suppression in total thyroidectomy cases were below $0.5 \mathrm{ng} / \mathrm{mL}$ by 6 months postoperatively, and sensitive for absence of thyroid remnant [4]. In the present study, we considered thyroid scan and basal $\mathrm{Tg}$ levels in normal condition

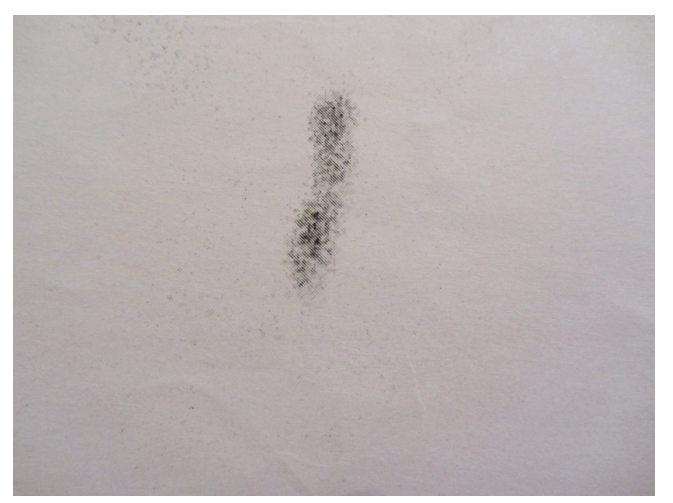

Figure 1. Remnant of thin pyramidal lobe. Nuclear scan and $\operatorname{Tg}$ positive $(2.7 \mathrm{ng} / \mathrm{mL})$; true positive. 


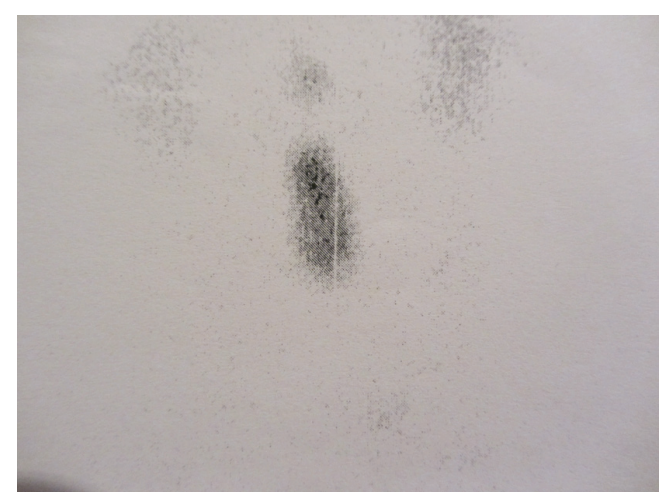

Figure 2. Remnant of the pyramidal lobe. Nuclear scan and Tg positive $(6.45 \mathrm{ng} / \mathrm{mL})$; true positive.

(normal "not suppressed" TSH levels) for the assessment of completeness of thyroidectomy 6 months postoperatively after total excision. Because thyroid gland is the only source of $\mathrm{Tg}$ production, serum basal Tg levels in benign cases could indicate the completeness of thyroidectomy.

In negative scan patients of the present series, the $\mathrm{Tg}$ levels $(<0.5 \mathrm{ng} / \mathrm{mL})$ were also negative, whereas all the Tgpositive patients also presented positive scan images showing thyroid remnants. We found a correlation (both scan and $\mathrm{Tg}$ level were negative or both were positive) between the results of nuclear scan and basal $\mathrm{Tg}$ levels in $93 \%$ of the patients. Based on these results, it can be concluded that the positive basal Tg levels always reveal a remnant focus after total thyroidectomy. Imaging methods, especially nuclear scan, are indicated for the detection of thyroid remnant in benign cases with positive Tg level. In malignant cases, positive Tg level may indicate at least radioiodine treatment in some patients [5]. The measurement of Tg level combined with neck ultrasonography after total thyroidectomy may exclude the need for ablation in low-risk patients with $\mathrm{Tg}<1$ $\mathrm{ng} / \mathrm{mL}[6]$.

Conflicting results were observed in $7 \%$ of our patients. The nuclear scan was positive despite negative basal Tg levels (false negative Tg results), and no false positive results (negative scan despite Tg positive) were noted. In a previous study, Kucukalic-Selimovic et al [7] reported 7.7\% false negativity and $17 \%$ false positivity in their series. Based on the false negative $\mathrm{Tg}$ results observed in the present study, it can be concluded that the amount of thyroid tissue in the remnant foci determined by nuclear scan is not sufficient to produce elevated Tg levels in the basal status. Lim et al [8] observed positive scan results (thyroid bed uptake) despite negative $\mathrm{Tg}$ levels in $11.3 \%$ of their patients, and negative scan results despite positive $\mathrm{Tg}$ levels in $16.2 \%$ of their patients. Furthermore, in the follow-up period, the authors found no remarkable differences in the clinical outcome of the positive scan, Tg-negative cases [8]. Zanotti-Fregonara et al [9] speculated that in the negative-scan, Tg-positive

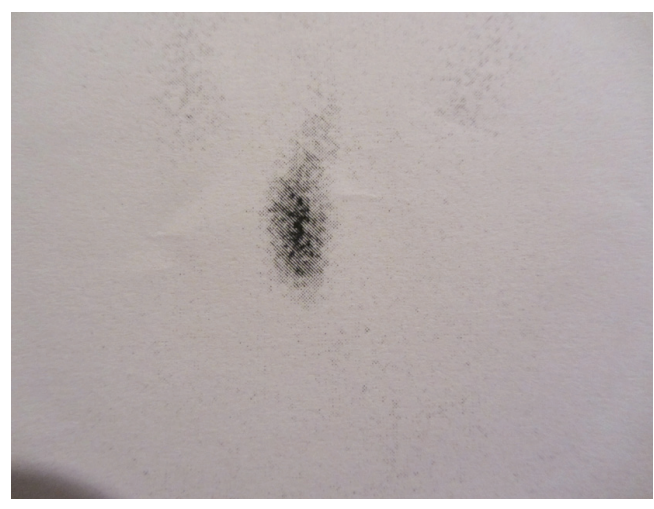

Figure 3. Small remnant of the upper part of the pyramidal lobe. Positive nuclear scan despite $\mathrm{Tg}$ negative (0.394 ng/ $\mathrm{mL})$; false negative.

cases, the benign sources of $\mathrm{Tg}$ secretion may be the foci of radio-resistant ectopic thyroid tissue. The presence or absence of thyroid remnant may be determined by nuclear applications. Unmeasurable Tg level $(<1 \mathrm{ng} / \mathrm{mL})$ shows surgical completeness of thyroidectomy $[10,11]$.

It has been reported that a biochemical marker should have high PPV and NPV to accurately identify patients with thyroid remnant and reduce unnecessary diagnostic studies, respectively [1]. The PPV and NPV of the Tg level $(<0.5$ $\mathrm{ng} / \mathrm{mL}$ ) obtained in the present study were $100 \%$ and $92 \%$, respectively. Rosario et al [6] observed that the NPV of the Tg level $(<1 \mathrm{ng} / \mathrm{mL})$ was $100 \%$. Similarly, several previous studies have reported high NPV of the Tg level indicating the absence of functional foci in patients with differentiated thyroid cancer $[12,13]$. In the present study, the PPV $(100 \%)$ of basal Tg level in benign cases revealed the presence of functional remnant foci after thyroidectomy. These foci may be imaged by nuclear scan to establish the site of radionuclide uptake in the thyroid bed. On the other hand, high NPV of the basal Tg level may exclude diagnostic imaging studies after total thyroidectomy in patients with benign thyroid disorders. Based on previous reports and the present study, it can be concluded that in benign cases, small remnants in nuclear scan associated with negative basal $\mathrm{Tg}$ levels do not have clinical significance for definitive treatment and recurrence.

Incomplete thyroidectomy may create some outcome problems. The lack of definitive treatment, risk of recurrences and secondary surgeries for both benign and malignant cases, and decrease in the sensitivity of follow-up for malignant cases are the main issues secondary to thyroid remnant after thyroidectomy. In the present study, PL remnants were found in majority of our patients in the initial period of study. In the recent study period, we performed careful dissection of the anterior central compartment up to hyoid bone to excise the entire thyroid tissue. It has been reported that identification of PL is uncommon in the preoperative period and 
that PL is not reliably diagnosed by scintigraphic imaging. Furthermore, the percentage of PL visualization by nuclear scan is approximately $15-20 \%$ [14-16]. These are the major drawbacks in thyroid surgery and can be a cause of incomplete resection of the gland; hence special attention has to be paid to PL $[15,16]$. The anterior cervical region has to be investigated very carefully during thyroidectomies. The surgeon should look for and identify PL, which should be mandatorily removed in total thyroidectomies to avoid leaving residual thyroid tissue after surgeries [15-17].

The high specificity and accuracy of serum Tg level in detecting the functional remnant of thyroid tissue after surgeries make it a promising tool for the assessment of the completeness of thyroidectomy. Serum Tg measurement is an easier and a preferred procedure for the detection of benign or malignant thyroid tissue in the follow-up after thyroidectomy. However, a minor drawback exists with respect to the sensitivity of the Tg level. Some small foci have inadequate amount of functional tissue to produce Tg in basal condition (positive scan and Tg negative), leading to false negative results of the Tg level. Previous studies have indicated that serial basal $\mathrm{Tg}$ measurements could elucidate doubtful gray conditions $[1,2,7,8,12]$. If the serial basal $\mathrm{Tg}$ levels remain negative in the follow-up period, it can be concluded that the clinical significance is very low and other diagnostic tools may be eliminated.

In conclusion, based on PL remnants in our cases anterior cervical region in the front of the trachea must be dissected carefully to evaluate the completeness of thyroidectomy in benign disorders of the gland. The basal serum Tg measurement is an easier tool to assess the remnant of functional tissue after thyroidectomy. The high PPV and NPV of the basal Tg levels make this glycoprotein a useful marker for the investigation of the completeness of thyroidectomy. In the postoperative period of benign cases, serum Tg level can be measured together with TSH, FT4 and anti-Tg ab levels to determine the hormone status of the patient as well as the completeness of excision.

\section{Conflict of Interests}

The authors declare that there is no conflict of interests regarding the publication of this article.

\section{References}

1. Zucchelli G, Iervasi A, Ferdeghini M, Iervasi G. Serum thyroglobulin measurement in the follow-up of patients treated for differentiated thyroid cancer. Q J Nucl Med Mol Imaging. 2009;53(5):482-489.

2. Rosario PW, dos Santos JB, Calsolari MR. Follow-up of patients with low-risk papillary thyroid carcinoma and undetectable basal serum thyroglobulin after ablation measured with a sensitive assay: a prospective study. Horm Metab Res. 2013;45(12):911-914.

3. Giovanella L, Suriano S, Ricci R, Ceriani L, Anton Verburg F. Postsurgical thyroid remnant estimation by ((9) (9)m) Tc-pertechnetate scintigraphy predicts radioiodine ablation effectiveness in patients with differentiated thyroid carcinoma. Head Neck. 2011;33(4):552-556.

4. Angell TE, Spencer CA, Rubino BD, Nicoloff JT, LoPresti JS. In search of an unstimulated thyroglobulin baseline value in low-risk papillary thyroid carcinoma patients not receiving radioactive iodine ablation. Thyroid. 2014;24(7):1127-1133.

5. Rosario PW, Mourao GF, dos Santos JB, Calsolari MR. Is empirical radioactive iodine therapy still a valid approach to patients with thyroid cancer and elevated thyroglobulin? Thyroid. 2014;24(3):533-536.

6. Rosario PW, Xavier AC, Calsolari MR. Value of postoperative thyroglobulin and ultrasonography for the indication of ablation and (1)(3)(1)I activity in patients with thyroid cancer and low risk of recurrence. Thyroid. 2011;21(1):49-53.

7. Kucukalic-Selimovic E, Alagic J, Valjevac A, HadzovicDzuvo A, Begic A, Beslic N. The value of serum thyreoglobulin levels and whole body (I-131) scintigraphy in the follow-up of the thyroid cancer patients after thyroidectomy. Coll Antropol. 2012;36(Suppl 2):67-71.

8. Lim DJ, O JH, Kim MH, Kim JH, Kwon HS, Kim SH, Kang MI, et al. Clinical significance of observation without repeated radioiodine therapy in differentiated thyroid carcinoma patients with positive surveillance whole-body scans and negative thyroglobulin. Korean J Intern Med. 2010;25(4):408-414.

9. Zanotti-Fregonara P, Keller I, Calzada-Nocaudie M, Al-Nahhas A, Devaux JY, Grassetto G, Marzola MC, et al. Increased serum thyroglobulin levels and negative imaging in thyroid cancer patients: are there sources of benign secretion? A speculative short review. Nucl Med Commun. 2010;31(12):1054-1058.

10. Holsinger FC, Ramaswamy U, Cabanillas ME, Lang J, Lin HY, Busaidy NL, Grubbs E, et al. Measuring the extent of total thyroidectomy for differentiated thyroid carcinoma using radioactive iodine imaging: relationship with serum thyroglobulin and clinical outcomes. JAMA Otolaryngol Head Neck Surg. 2014;140(5):410415.

11. Tae K, Song CM, Ji YB, Kim KR, Kim JY, Choi YY. Comparison of surgical completeness between robotic total thyroidectomy versus open thyroidectomy. Laryngoscope. 2014;124(4):1042-1047.

12. Giovanella L, Treglia G, Sadeghi R, Trimboli P, Ceriani L, Verburg FA. Unstimulated highly sensitive thyroglobulin in follow-up of differentiated thyroid cancer patients: a meta-analysis. J Clin Endocrinol Metab. 
2014;99(2):440-447.

13. Webb RC, Howard RS, Stojadinovic A, Gaitonde DY, Wallace MK, Ahmed J, Burch HB. The utility of serum thyroglobulin measurement at the time of remnant ablation for predicting disease-free status in patients with differentiated thyroid cancer: a meta-analysis involving 3947 patients. J Clin Endocrinol Metab. 2012;97(8):2754-2763.

14. Cengiz A, Saki H, Yurekli Y. Scintigraphic evaluation of thyroid pyramidal lobe. Mol Imaging Radionucl Ther. $2013 ; 22(2): 32-35$.
15. Geraci G, Pisello F, Li Volsi F, Modica G, Sciume C. The importance of pyramidal lobe in thyroid surgery. G Chir. 2008;29(11-12):479-482.

16. Braun EM, Windisch G, Wolf G, Hausleitner L, Anderhuber F. The pyramidal lobe: clinical anatomy and its importance in thyroid surgery. Surg Radiol Anat. 2007;29(1):21-27.

17. Zivic R, Radovanovic D, Vekic B, Markovic I, Dzodic $\mathrm{R}$, Zivaljevic V. Surgical anatomy of the pyramidal lobe and its significance in thyroid surgery. S Afr J Surg. 2011;49(3):110, 112, 114 passim. 